\title{
In Honour of the 70th Birthday of Professor Luis A. Oro
}

\author{
Fernando J. Lahoz* and Jesús J. Pérez-Torrente*
}

Departamento de Química Inorgánica, Instituto de Síntesis Química y Catálisis Homogénea - ISQCH, Universidad de Zaragoza-CSIC, 50009-Zaragoza, Spain.

E-mail:1ahoz@unizar.es,perez@unizar.es

When Professor Oro turns over the middle of June, he will be 70 years old, and he will be completing a cycle of almost half a century ( 48 years) dedicated to chemical research in the field of organometallics and homogeneous catalysis, and in general to the development of Chemistry. In this aim, he has assumed different and complementary responsibilities, from leading innovative research projects, to the formation of professional scientists for the academia or chemical industry, from the direction of the Spanish Royal Society of Chemistry, to that of diverse editorial management consortia or even having taken the responsibility of guiding the overall Spanish scientific policy.

It has been a long trek done with tons of enthusiasm, excellent criteria and plenty of generosity. It is our pleasure and privilege to walk around the main steps of Professor Oro's life; a life dedicated to investigate and to work to situate chemical research, and Science in general, in the proper place it should be in our modern society.

\section{A lively young}

Luis Oro was born in a small rural neighbourhood on the outskirts of the city of Zaragoza, in northeastern Spain, in a humble but well educated family for the standards of those days in Spain. His mother was the school teacher of a unitary public school where children aged 6 to 12 years shared the same classroom. His father, also a teacher, had suffered some retaliation by the authoritarian government of Franco regime for his liberal ideas, and had been fortunately received in a private school in the main city where he was teaching at secondary level.

The extraordinary influence of his mother to maintain a constant state of learning, that of his father, always considering how to evolve, to change, to find better ways of coping with life and that shared by both of them, in terms of being always ready to teach, to 
transmit their knowledge, shaped in his son a critical character, markedly dynamic and quite generous.

His early years in the school, sharing space with older classmates and with his mother/teacher anytime available, stimulated a rapid learning, also supported by his peculiar genetics quite well equipped for fast analysis of problems and situations, and with an energetic dynamism and extraordinary physical strength.

Being 10 years old, his family moved to live in the city centre, among other circumstances to favour the education of Luis and his brother Lorenzo. Luis Oro began his secondary studies at the Escolapios private school, where his father was working. This school was a well-known institution, recognised at that time by an extremely strict education, which restricted the creative abilities of young teenagers, but provided a very good training. We know that Luis Oro do not have good memories of those days.

During these years, Luis Oro spent all his long summer holidays in the village where his mother was born, Burgasé, a very small village in the south of the central Pyrenees, surrounded by cows and mountains. There, Luis Oro would get a taste for the beauty of mountains and a passion for the mountain sports, love he still keeps moving.

Luis Oro studied chemistry at the University of Zaragoza, where he graduated in 1967, not without leaving a trace of their passage in the Faculty of Sciences. In his mind still remains the memory of several excellent professors as Juan Martín Sauras o Julián Bernal. His love for mountains and enthusiasm for sport, lead him in 1966 to combine his last year as undergraduate student and as member at the Spanish national team of Nordic skiing. Despite the large number of skiing training hours, his enormous capacity for work and his extraordinary intellectual talent enable him to overcome his graduation with very good grades. During this year of 'good life' in the mountains, Luis Oro made some friends that he has maintained all along his life. He developed another of his personal skills, his capacity to persuade colleagues and friends to follow him in a particular challenge; in fact, some of his teammates at the national ski team would end up studying in Zaragoza and sharing with him their academic life at the University of Zaragoza, that was the case of his friend and well recognized psychiatrist Antonio Lobo.

In the fall of 1967, Luis Oro began his PhD studies under the direct supervision of Dr. Fermín Gómez Beltrán in the Physical-Chemistry Department at Zaragoza University. 
His extraordinary work capacity, and his abilities to have his mind working in several projects, allowed Luis Oro to progress in the experimental part of his thesis preparing his first new coordination compounds; during the same period, he had time to maintain his training for skiing competition, carrying out both activities at very high level. In the winter of 1968, Luis Oro represented Spain, as a member of the Spanish Nordic skiing team, in the University Youth Winter Olympiads in Innsbruck (Austria).

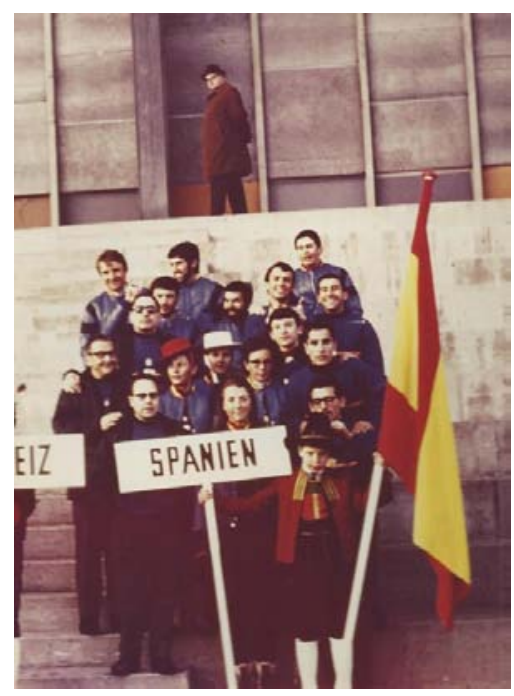

Luis Oro with his teammates of the Spanish Nordic Ski team at the University Winter Olympiads; he is in the third row on the right ( (1968, Innsbruck)

In the spring of that year taken by his passion for mountaineering,- with other university partners as was his friend unfortunately deceased surgeon José Ramón Morandeira,they founded the University Alpine Club still active nowadays (http://goo.gl/YXxhjv). This initiative, independent to all sports initiatives of the Spanish rigid regime at that time, put them completely out of the tough political system. Luis Oro and his companions were investigated and called to be presented at the local government to explain this audacity to the officials of the regime, but fortunately, despite their daring, they do not suffer any punishment because they were considered just athletes without any political component (and because the father of one of them was involved in the local government!). 


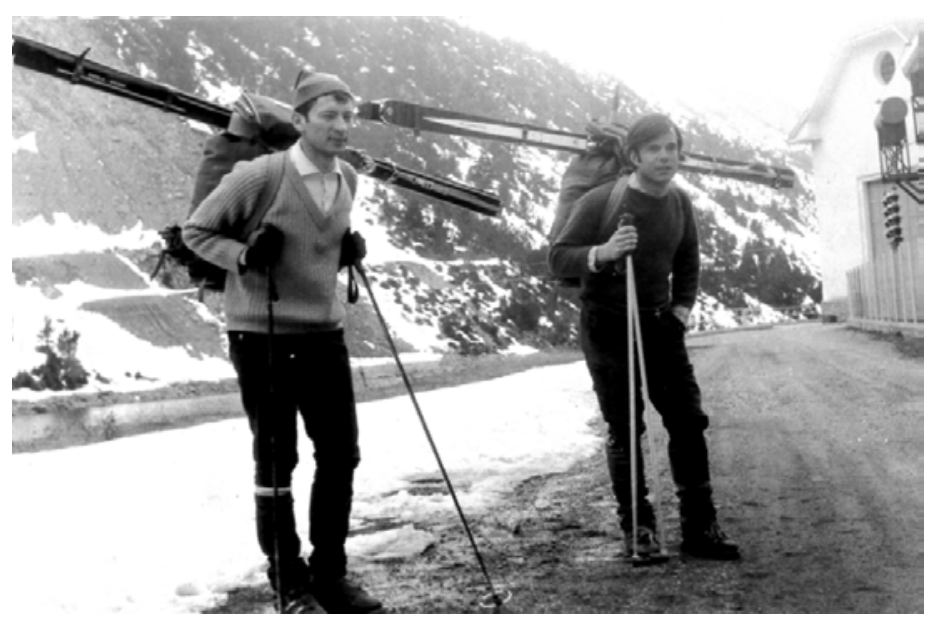

Luis Oro with his friend, and co-founder of the University Alpin Club, José Ramón Morandeira, before a mountaineering ski tour (1968, Spanish Pyrenees)

Winter of 1969 was a crucial period in the life of Luis Oro. Trying to get some extra money for his student pocket, he was working as ski instructor in the weekend courses organized at the University Alpine Club. In one of these courses he met a pretty young lady, Tuca, with whom he would get some friendship, and soon he will fall in love with. She would be the mother of his children: Luis, Begoña and Esther, and she has been giving him support all along his career.

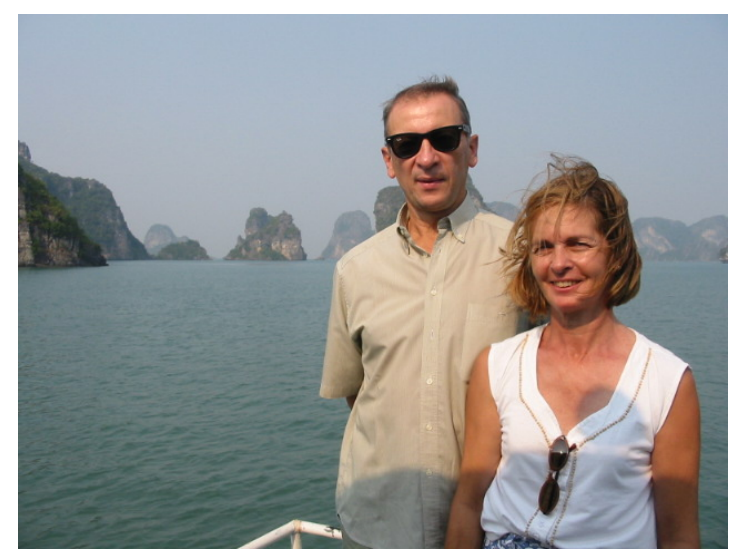

Luis Oro his wife Tuca some years later in the Ha Long Bay (2003, Vietnam)

In September 1970, Luis Oro submitted his doctoral thesis entitled "Magnetochemical and Spectroscopic Study of Oxinate Cobalt(II) Complexes". He soon understood that if he wanted to be a top scientist, he would need to work and learn in the most advanced international labs. Trying to properly progress in the research line of his $\mathrm{PhD}$ thesis, on the magnetic properties of paramagnetic cobalt complexes, he travelled with a posdoc fellowship to the University of Leiden (Kamerling Onnes Lab) in the summer of 1971. 
This stay allowed him to finish his studies on cobalt complexes, but he felt he would like to have a longer experience, working in a more state-of-the-art topic.

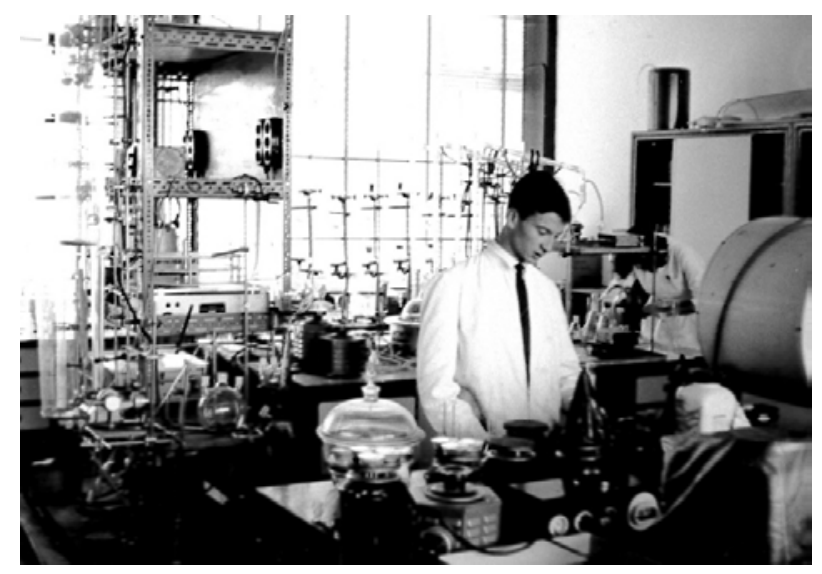

Luis Oro in the Kamerling Onnes lab in his first posdoc stay (1971, Leiden)

In 1972 he moved to the University of Cambridge (United Kingdom) with a Juan March grant, trying to approach other frontier research lines. There, he would work in the laboratory leaded by Professor Jack Lewis, being introduced to the synthesis of the first organometallic compounds and collecting innovative ideas on the emerging area of homogeneous catalysis. On his return to the University of Zaragoza, in 1973, he got a permanent position as Lecturer in the Department of General Chemistry, and started a determined work for the creation of a working group that could exploit his experience in coordination and organometallic chemistry to investigate the application of this type of complexes in catalytic processes in homogeneous phase.

\section{(Prof. C. Claver text around here)}

His tenacity in the lab, his chemical intuition, his innovative ideas and his team leadership capacity, allowed him to quickly create a quite strong group on Inorganic Molecular Chemistry, Organometallics and Homogeneous Catalysis. Clever and hard worker students in the late seventies and early eighties joined his promising group and soon they were embedded by his passion for high standards chemical research; names like Claver, Garralda, Ciriano, Carmona, Lahoz, Esteruelas, and others joined Profesor Oro's group and are nowadays well known researchers in this field.

In 1976, Luis Oro gets a Reader position in Inorganic Chemistry in the very competitive Complutense University in Madrid, where he stayed only for a year, returning again to 
his native Zaragoza University in 1977, already as Reader in Chemistry. In 1981, his excellent research results, together with his well-recognized communication capacities, permitted him to win a Full Professor position in Inorganic Chemistry at Santander University. One year later, the University of Zaragoza offered him the Chair in Inorganic Chemistry where he has been working as full Professor to the present day.

A remarkable labour done along all these years has been the formation of a large number of disciples. The first thesis begin in the 70s and almost 50 doctors have been formed under his leadership, many of whom today are researchers, academics, or occupy important positions in Spanish and international companies. It is worth noting the long history of the research group he leads, which today welcomes mainly European doctoral and post-doctoral students from different countries of the world. More than 60 post-doc or doctoral students have spent periods of training in his laboratory, where it is common to find famous foreign colleagues on a sabbatical leavel.

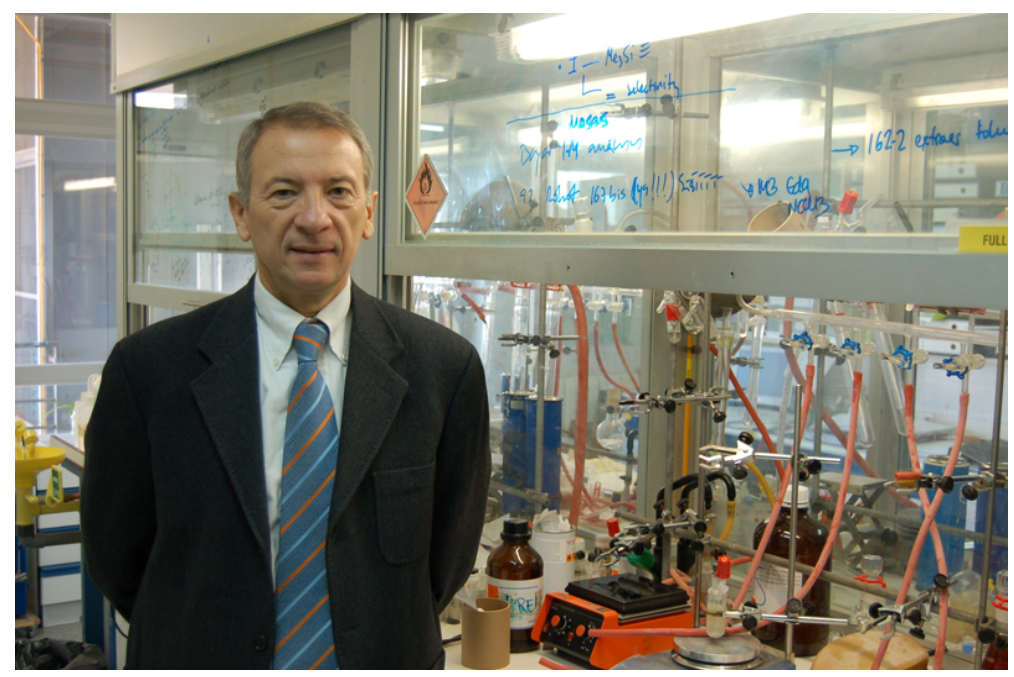

Luis Oro in his current lab in the Institute of Synthetic Chemistry and Homogeneous Catalysis (ISQCH) (2014, Zaragoza)

\section{Tracking the Chemistry}

\section{The Chemistry: a look back}

Prof. Luis Oro's scientific achievements are reflected in nearly 600 papers he has published. His research has been focused on the Coordination and Organometallic 
Chemistry of platinum group metals and Homogeneous Catalysis. His scientific career started in the middle seventies and since then he has made outstanding contributions at the forefront of Chemistry both in fundamental and applied research. These achievements had not been possible without a talented and well-motivated research team composed of several excellent chemists. Unfortunately, some group members passed away too early and will forever be remembered by all of us.

His first contributions were made on rhodium chemistry in collaboration with Prof. Rafael Usón. The synthesis of a range of mononuclear cationic diene rhodium(I) complexes with monodentade $\mathrm{N}$ - and $\mathrm{P}$ - donor ligands was followed by those of bidentate ligands some of which showed to be hydrogenation, transfer hydrogenation and hydroformylation homogeneous catalysts. Not long thereafter the asymmetric hydrogenation of several prochiral substrates using neutral and cationic complexes, modified with a chiral diphosphine, was carried out in collaboration with Prof. C. Cativiela. ${ }^{1}$ Key research workers in the team by then were, among others, Carmen Claver and M. Angeles Garralda, nowadays full Professors in the Universidad del País Vasco (UPV/EHU, San Sebastián) and Universitat Rovira i Virgili (URV, Tarragona), respectively.

The synthesis of pyrazolate bridged dinuclear rhodium complexes was first reported in the early eighties, and represented the starting point for the development of the chemistry of dinuclear and polynuclear rhodium and iridium complexes in the group. ${ }^{2}$ This chemistry was quickly expanded by using several N-donor heterocyclic ligands which also allow for the preparation of interesting heterobimetallic complexes. The pyrazolate-bridged dinuclear rhodium complexes were found to be active in hydroformylation and thus, several dinuclear complexes having mixed-bridged ligands, pyrazolate and thiolate, were prepared in our group by Dr. M. Teresa Pinillos in collaboration with Prof. Philippe Kalck from Laboratoire de Chimie de Coordination of the CNRS in Toulouse (France). The pyrazolate dinuclear chemistry based on $\mathrm{Cp} * \mathrm{M}(\mathrm{III}) \quad(\mathrm{M}=\mathrm{Rh}, \mathrm{Ir} ; \mathrm{Cp} *$ = pentamethylcyclopentadienyl) and (arene)Ru(II) metal fragments, including a diversity heterobimetallic and heterotrimetallic complexes, was also developed in our group by Prof. Daniel Carmona in collaboration with Drs. Montserrat Esteban and Josefina Reyes. ${ }^{3}$ Remarkably, the reversible isomerization of a 
ruthenium-iridium dinuclear complex involving the formation of a metal-metal bond was unveiled. ${ }^{4}$

Along this time the group got benefited from the valuable collaboration of Profs. Félix H. Cano and Concepción Foces-Foces (Instituto de Química Física Rocasolano, CSIC, Madrid); and Profs. Antonio Tiripichio and Marisa Tiripichio-Camellini (Università degli Studi di Parma, Italy) that helped us in the structural characterization of great number of compounds, essential information to keep the research stream going. As the complexity of the molecules was increasing, the structural determination was becoming more and more difficult and the intermolecular interactions were identified quite relevant to understand reactive processes. At this point, Prof. Oro convinced a young post-doc, Dr. Fernando J. Lahoz, to learn structural techniques. After several post-doc periods in Madrid, Parma and Cambridge, Prof. Lahoz come back to Zaragoza and established a structural state-of-art lab facility; he has been given, as expert chemical crystallographer, structural support to most of Prof. Oro's group research.

The progress in polynuclear chemistry followed two different synthetic approaches in the group along the nineties. On one hand, Dr. M. Teresa Pinillos made use of triazolate, benzotriazolate and several functionalized triazole ligands for the preparation of a range of polynuclear complexes with unusual molecular architectures. ${ }^{5}$ On the other hand, Prof. Miguel A. Ciriano undertakes the synthesis of low nuclearity rhodium and iridium complexes by using bridging ligands containing the $\mathrm{N}-\mathrm{C}-\mathrm{X}(\mathrm{X}=\mathrm{N}, \mathrm{O}, \mathrm{S})$ structural unit. Supporting ligands including 1,8-naphthyridine, 7-azaindolate, 2pyridonate, 1,8-naphthyridine-2-onate, pyridine-2-thiolate or benzothiazole-2-thiolate allowed the controlled synthesis of a diversity of di- and polynuclear complexes. ${ }^{6}$ Noteworthy, the stepwise construction of mono- di- tri- tetra- and hexa-nuclear complexes based on benzimidazole-2-thiol ligands was achieved. The synthesis of rhodium tetranuclear complexes driven by 2,6-pyridinedithiolate ligands as buildingblocks for more complex inorganic architectures was also remarkable. The reactivity of dinuclear rhodium and iridium complexes was largely investigated looking for new reactivity patterns arising for the close proximity of the metal centres, in particular oxidative addition reactions. In this context, electron-rich pyrazolate-bridged rhodium and iridium complexes having isocyanide ligands as auxiliary ligands were found to be able to activate a range of chloro-alkanes giving rise to an unusual reactivity through 
cooperative effects. ${ }^{7}$ One exciting finding was the isolation of a mixed-valent linear iridium tetranuclear cluster as an intermediate species in a oxidative addition reaction in route to the dinuclear metal-metal bonded iridium(II). ${ }^{8}$ Interestingly, this compound was the first precedent of a new family of rhodium and iridium blues, closely related to the well-known platinum blues. Later on, the rational design of discrete mixed-valence metal chains by redox condensation processes between rhodium or iridium dinuclear complexes in different oxidation states allowed Dr. Cristina Tejel, in collaboration with Dr. B. Eva Villarroya, the preparation of tetra- and hexametallic chains composed of dinuclear units having pyrazolate or 2-pyridonate bridging ligands and exhibiting electron delocalization along the chain. ${ }^{9}$

A fruitful collaboration with the group of Prof. J. Luis Serrano was established in the early nineties based on the application of coordination chemistry to the preparation of advanced materials. Transition metal based liquid crystals including copper, silver, rhodium and iridium mononuclear complexes were reported, with those made of dinuclear rhodium(II) (alkyloxy)benzoate complexes, and trinuclear gold(I) pyrazolate complexes in collaboration with Dr. A. Elduque, were of significant relevance. ${ }^{10}$

At the same time Prof. Luis Oro attention turned out into iridium, ruthenium and osminun chemistry. Dr. M. Jesús Fernandez explored the organometallic chemistry of poly(pyrazolyl)borato iridium complexes describing their interesting reactivity for the activation of carbon monoxide. ${ }^{11}$ In addition, the synthesis of outstanding dihydridosilyl-iridium(III) complexes and their catalytic activity in dehydrogenative hydrosilylation of alkenes was also reported. Prof. Miguel A. Esteruelas also contributed to the organometallic chemistry of iridium mononuclear complexes having basic $\mathrm{P}$-donor ligans $\left(\mathrm{PCy}_{3}\right.$ and $\left.\mathrm{P}^{\mathrm{i}} \mathrm{Pr}_{3}\right)$, and to the design of $\mathrm{Ru}-\mathrm{Ir}$ and $\mathrm{Ru}-\mathrm{Rh}$ heterodinuclear complexes containing azolate bridging ligands, in collaboration with Prof. M. Pilar Garcia. These later complexes showed indirect cooperative effects leading to synergism in bimetallic homogeneous hydrogenation and hydrogen transfer hydrogenation catalysis. ${ }^{12}$ On the other hand, a series of pyrazolate bridged ruthenium(I) complexes and trinuclear carbonyl ruthenium clusters with nitrogencontaining heterocycles were prepared in our group by Prof. Javier A. Cabeza, who has made significant contributions to cluster chemistry at the University of Oviedo as an independent researcher. Prof. Miguel A. Esteruelas developed the osmium chemistry in 
the group. The synthesis and reactivity studies on several polyhydrido osmium complexes resulted in a rich organometallic chemistry including carbon-carbon coupling and carbon-hydrogen activation reactions. Noteworthy, complex $\mathrm{OsHCl}(\mathrm{CO})\left({\mathrm{P} i \mathrm{Pr}_{3}}_{2}\right)_{2}$ can be considered as one of the cornerstones in the development of modern organometallic osmium chemistry. ${ }^{13}$ In addition, the role of dihydrogen complexes as intermediates in catalytic reactions was also established. Along this stage, collaboration with Prof. Helmut Werner (University of Würzburg), who had realized on the strong influence of the phosphine ligand on the reactivity of organometallic species, was of great significance in this chemistry.

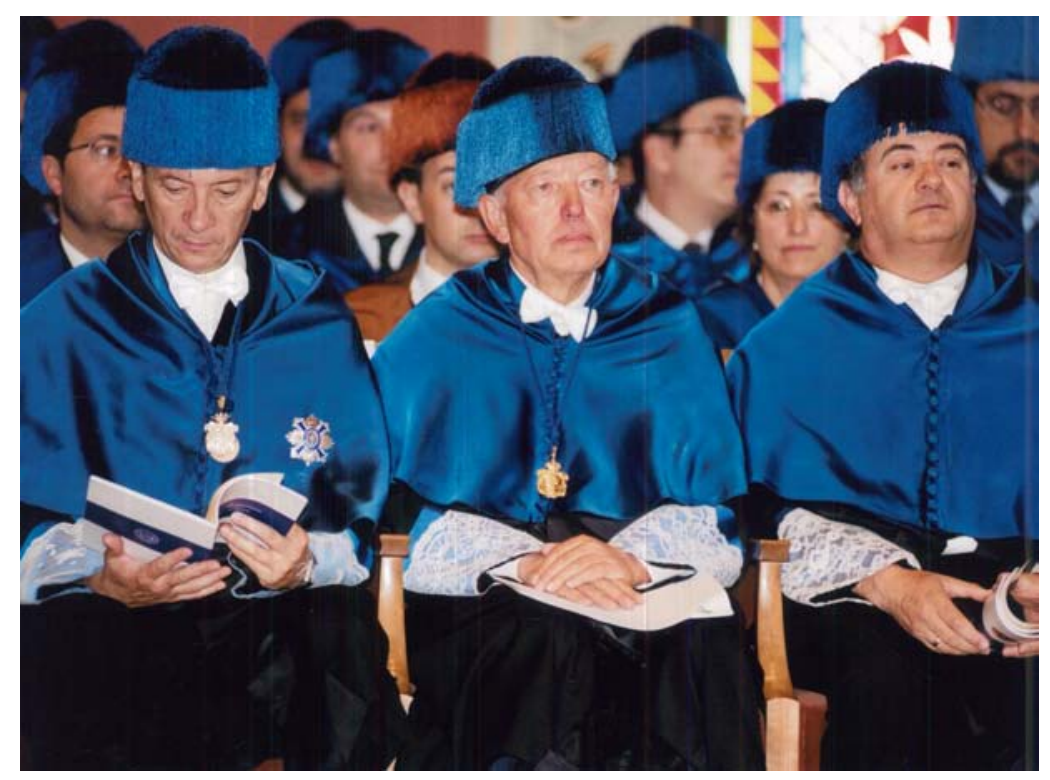

During Prof. Helmut Werner's Honoris Causa Doctorate ceremony; Luis Oro (left) and Prof. Antonio Laguna (right) (2001, Zaragoza)

The ability of pentafluorophenyl ligand for the stabilization of unusual oxidation states in platinum chemistry encouraged the exploration of the chemistry of perhalophenyl derivatives of rhodium and iridium. Prof. M. Pilar García carried out the first synthesis of anionic aryl Rh(III) complexes in the late eighties. ${ }^{14}$ Later on, this chemistry was further expanded with the preparation of unprecedented square planar $\mathrm{Rh}(\mathrm{II})$ and $\mathrm{Ir}(\mathrm{II})$ complexes stabilized by pentachlorophenyl ligands. ${ }^{15}$

The first report on the synthesis of chiral at metal transition metal complexes in our group dates from the early nineties. ${ }^{16}$ Since then, Prof. Daniel Carmona, in straight collaboration with Prof. Pilar Lamata, Drs. Fernando Viguri and Joaquina Ferrer have conducted the synthesis of a range of optically active pseudoctahedral rhodium(III), 
iridium(III), and ruthenium(II) complexes which has been successfully applied as catalysts in a range of enantioselective transformations including Diels-Alder, transfer hydrogenation of ketones, cyclopropanation and Michael reactions, which constitute a research area of great impact. ${ }^{17}$ Outstanding contributions have also been made in the 1,3-dipolar cycloaddition reactions of nitrones with methacrolein including the full characterization of key catalytic intermediates and the investigation of the origin of the enantioselectivity. ${ }^{18}$

The chemistry of polynuclear metal complexes was further expanded in the group in the 2000 s following two very different synthetic strategies that lead to the preparation of a series of clusters with new exciting and unusual structures. Prof. Miguel A. Ciriano and Dr. Cristina Tejel developed the chemistry of tetranuclear imido rhodium-diene clusters. The carbonylation of these clusters resulted in a structural rearrangement resulting from reversible migration of a metal fragment. ${ }^{19}$ Noteworthy, the synthesis of a hexametallic rhodium cluster with a doubly-spiked square through the formation of unsupported metal-metal bonds, was achieved by dimerization of a anionic trinuclear imido complex promoted by oxidation. ${ }^{20}$ Noteworthy, some dinuclear amido rhodium precursors were used as a platform for the controlled synthesis of heterotrinuclear complexes with a range of transition metals. Profs. Miguel A. Ciriano and Jesús J. Pérez-Torrente designed a synthetic strategy to entry into the chemistry of early-late heterobimetallic complexes (ELHB) based on the additive deprotonation of bis-hydrosulfido titanium and zirconium complexes with mono- and dinuclear $\mathrm{d}^{8}$ rhodium and iridium compounds having basic ligands. This strategy led to the preparation of $\mathrm{d}^{0}-\mathrm{d}^{8}$ sulfido-bridged clusters and aggregates with unusual structures, as for example the expected heterotrinuclear complexes with a triangular $\left[\mathrm{ZrM}_{2}\right]$ core capped with two sulfido ligands, but also unexpected clusters of composition $\left[\mathrm{TiM}_{3}\right](\mathrm{M}=\mathrm{Rh}, \mathrm{Ir}) .{ }^{21}$ Noteworthy, the carbonyl $\left[\mathrm{ZrIr}_{2}\right]$ compound is a precursor for the synthesis of early-late heterotrimetallic (ELHT) complexes with $[\mathrm{ZrIrM}](\mathrm{M}=\mathrm{Rh}, \mathrm{Pd}, \mathrm{Au})$ metal cores by metal exchange reactions. ${ }^{22}$

Dr. Eduardo Sola in the early 2000s retook the chemistry of diamidonaphthalenebridged dinuclear complexes, that was initiated by Dr. M. Jesús Fernandez in the late eighties, and that of pyrazolate bridged dinuclear complexes. Reactivity studies on these iridium dinuclear complexes allowed discovering unusual $\mathrm{C}-\mathrm{H}$ activation processes and 
key mechanistic aspects of dihydrogen activation and catalysis, including the transmission of trans effects in dinuclear complexes. ${ }^{23}$ The chemistry and catalytic activity of hydride iridium triisopropylphosphine complexes were also investigated as well as that of iridium cyclooctadiene complexes. Interestingly, the factors involved in the isomerization of cyclooctadiene ligand at iridium centre initiated by intramolecular $\mathrm{C}-\mathrm{H}$ activation were identified. ${ }^{24}$ On the other hand, smart mechanistic studies on imine hydrogenation catalyzed by mono- and dinuclear iridium complexes based on meticulous NMR studies were also conducted in collaboration with Dr. Marta Martín. ${ }^{25}$

From this point the chemistry developed in the group took new directions that led to exceptional findings both in chemical synthesis and catalysis. Dr. M. Victoria Jiménez started a project for the design of new catalyst precursors based on functionalized phosphine ligands of hemilabile character. Rhodium(I) complexes having alkoxofunctionalized phosphine ligands were found to be efficient catalysts for the antiMarkovnikov oxidative amination of styrene with excellent activities and enamine selectivity. Mechanistic studies allowed the identification of a key amido intermediate as the active species, which was further supported by theoretical calculations carried out by Dr. F. Javier Modrego. ${ }^{26}$ On the other hand, cationic rhodium(I)-diene complexes having hemilabile phosphines were also efficient initiators for the stereoregular polymerization of phenylacetylene giving polymers with an outstandingly high molecular weight. Mechanistic investigations revealed the formation of a key alkynyl species, resulting from a proton transfer processes to the hemilabile fragment of the ligand, as the initiator species. ${ }^{27}$

In 2007, Dr. Ramón Macias initiated a research project focused on the development of new polyhedral cluster focused on potential applications in catalysis. The synthesis of new metallathiaboranes and the study of their structures and reactivity showed the strong influence of the polyhedral ligand on the properties of the metal centre. In this context, it was discovered a new system capable of undergoing the addition of dihydrogen into the three-dimensional framework which opens new routes for potential catalytic hydrogenation. $^{28}$

\section{The Chemistry: a look forward}


In the last recent years, we have been witnesses of impressive advances both in the design of new catalysts and the understanding of the reaction mechanism as a consequence of the expertise gained in the group that encouraged the undertaking of more ambitious and risky projects. Furthermore, the incorporation of new enthusiastic senior scientists in the Prof. Luis Oro's group has also allowed moving the chemistry towards new directions. In particular, the involvement of Dr. Victor Polo having great expertise on theoretical calculations has been fundamental for the successfully development of this chemistry.

The catalyst design based on functionalized N-heterocyclic carbene ligands (NHCs) of hemilabile character has also been a major target in the group after disclosing efficient rhodium(I) hydrosilylation catalyst based on amino-alkyl functionalized NHC ligands by Dr M. Victoria Jiménez in 2008. ${ }^{29}$ In fact, Dr. Manuel Iglesias has developed new rhodium and iridium(III) catalyst based on bis-NHC hemilabile ligands that allow for the control of the regioselectiviy in the hydrosilylation of alkynes. Interestingly, an outer-sphere ionic mechanism involving the acetone solvent has been proposed to be responsible for the $\beta-Z$ hydrosilylation of terminal alkynes. ${ }^{30}$

Neutral and cationic rhodium and iridium(I) complexes based on hemilabile O- and Ndonor functionalized NHC ligands were also found to be efficient catalysts for the transfer hydrogenation of a range of unsaturated substrates. Looking for the effect of the support on the catalytic activity, several strategies for the covalent immobilization of IrNHC complexes on carbonaceous supports have been established. Dr M. Victoria Jiménez, in collaboration with Prof. Rosa Menendez at INCAR (Instituto Nacional del Carbón, Oviedo), has prepared iridium hybrid materials based on carbon nanotubes and graphene oxide with catalytic activity in hydrogen transfer reactions exhibiting good recyclability and stability. ${ }^{31}$ Following a different strategy, Dr. Francisco FernándezAlvarez, in collaboration with Dr. Pablo Sanz Miguel, has prepared Rh(I)-NHC complexes functionalized with a triisopropoxysilyl tail group for their immobilisation on silica-based inorganic supports. The hybrid materials have found application in the catalytic hydrosilylation of ketones, hydrodechlorination of benzyl chloride, and in the synthesis of high molecular weight poly(silylether)s by catalytic hydrosilylation. A breakthrough development was the synthesis of a highly stable iridium(III) catalyst based on a tridentate NSiN ligand that effectively promotes the hydrosilylation of $\mathrm{CO}_{2}$ 
to silyl formate under very mild conditions without a solvent. ${ }^{32}$ As it was suggested by theoretical calculations, the reaction proceeds by an outer-sphere mechanism, which opens new possibilities for catalyst design.

On the other hand, the synthesis of a diversity of Rh-NHC complexes containing a bulky NHC ligand by Dr. Ricardo Castarlenas has allowed understanding the electronic factors that control the coordination preferences on the Rh-NHC fragment. This has facilitated the design of new catalysts for several relevant transformations including the selective H/D exchange at the $\beta$ position of aromatic $\alpha$-olefins, ${ }^{33}$ or the hydrothiolation of alkynes with control of the regioselectivity towards the $\alpha$-vinyl sulfide product in which a pyridine effect has been recognized. ${ }^{34}$ In addition, the Rh-NHC catalytic systems under investigation have been applied to several processes involving $\mathrm{C}-\mathrm{C}$ bond forming reactions including the head-to-tail dimerization of terminal alkynes to give gem-enynes, the cross-dimerization and cross-trimerization of alkynes with silylacetylenes also with gem selectivity, ${ }^{35}$ and the selective coupling of $\mathrm{N}$ vinylpyrazoles with alkynes via $\mathrm{C}-\mathrm{H}$ activation, being the later a rather challenging reaction. ${ }^{36}$ Noteworthy, the hydrovinylation of terminal alkynes with 2-vinyl pyridine provide access to $4 \mathrm{H}$-quinolizines, a N-bridgehead bicyclic compound, by electrocyclization of the Z-gem-butadienylpyridine coupling product. $^{37}$

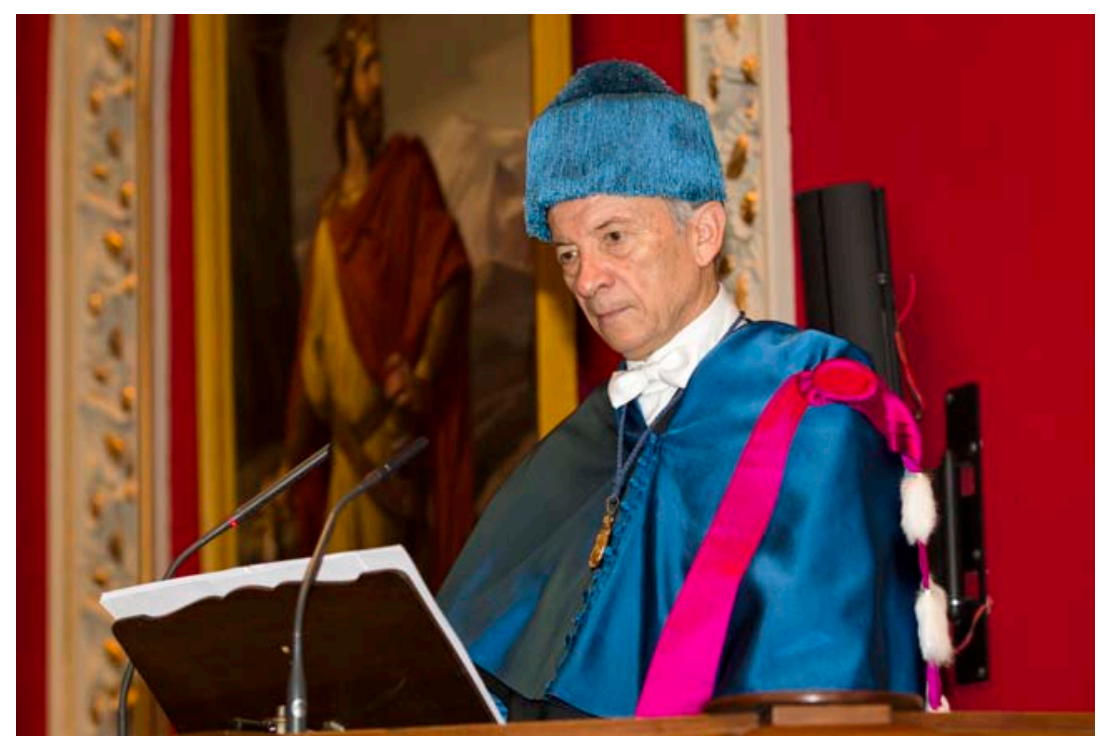

Luis Oro giving the main lecture at the University Assembly Hall in San Braulio's Day, patron saint of Zaragoza University (2013, Zaragoza)

Metal-mediated catalytic functionalization of ammonia is a hot topic. In this context, the clever choice by Dr. Miguel A. Casado of organometallic methoxo-bridged diiridium 
and dirhodium precursors led to a facile $\mathrm{N}-\mathrm{H}$ heterolytic activation of ammonia allowing the preparation of very rare parent amido complexes $\left[\mathrm{M}-\mathrm{NH}_{2}\right](\mathrm{M}=\mathrm{Ir}, \mathrm{Rh}), \mathrm{a}$ scenario that has enlighten novel concepts. ${ }^{38}$ Dinuclear amido complexes of iridium(I) are active catalysts in hydrogen transfer processes, in which a binuclear metal-ligand cooperative mechanism is operative. These species also participate in stoichiometric $\mathrm{C}-$ $\mathrm{NH}_{2}$ bond formation processes, transformations quite relevant to catalytic hydroamination of unsaturated substrates with ammonia. ${ }^{39}$

The advance of ongoing projects is also expected to have an impact on the future research activity of the group. In particular, a systematic modification of the chemical basis of metallathiaboranes clusters has been planned in order to enhance in a control manner their reactivity. A very important step forward has been the use of carbene ligands bound to the metal centre, or the protonation of the cages with strong Brønsted acids. $^{40}$ Both procedures enhance dramatically the reactivity of the polyhedral clusters towards small molecules, opening new opportunities for the development of catalytic chemistry. The Friedel-Crafts reaction is a powerful strategy for the alkylation of aromatic and heteroaromatic substrates and in fact, the design of chiral transition-metal as Brønsted-acid catalysts for the asymmetric Friedel-Crafts reactions is a leading research topic currently under investigation in the group. ${ }^{41}$ Finally, the progress in sulfido cluster chemistry entails the direct use of $\mathrm{H}_{2} \mathrm{~S}(\mathrm{~g})$ as sulfido- or hydrosulfido ligand source for the synthesis of transition-metal clusters with potential catalytic activity. $^{42}$

\section{Not only Synthetic Chemistry or Catalysis}

Together with the vast and continuous research activity we have briefly summarized above, Prof. Luis Oro has maintained all along his scientific career a series of different and complementary activities contributing to a better positioning of Chemistry in particular, and Science in general, in our modern society. Let us just comment on his relevant contributions to the Science policy in our country and some other responsibilities assumed by Luis Oro in the past.

The arrival of democracy to the Spanish society in the beginning of the eighties, marked the entrance in the Spanish administration of a group of young professionals who had to revise the general organization of the state, including the whole education system and 
the structure of scientific research and its role in the establishment of a modern society. In 1986, the Ministry of Education and Science restructured and organized all the aspects of scientific and technical research in Spain; they approved the 'Law on Science', as we now it nowadays.

In the previous years, Luis Oro had participated in some committees assessing research projects in the Chemistry area and obviously he had exhibited his excellent personal abilities for management, both in quantitative and qualitative terms. Luis Oro in 1987 was appointed as 'General Director of Technical and Scientific Research' at the Ministry of Education and Science, and its excellent management led him to occupy the 'General Secretary of the National Plan for Scientific Research and Technological Development' in 1988.

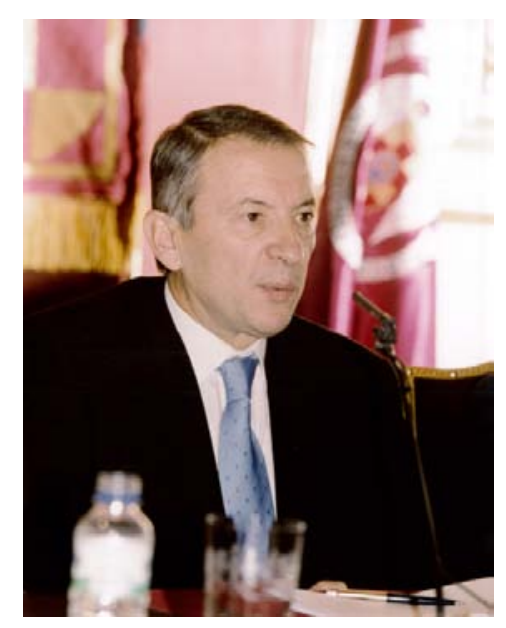

Luis Oro talking in his office as General Secretary of the National Plan for Scientific Research and Technological Development (1989, Madrid)

He had in his hands the great responsibility of organizing all the instruments to make Spain competitive in Science and Technology (organization, general or specific calls, participation in European initiatives, planning a young researcher grant system, etc.). He was during almost seven years working hand by hand with the Spanish Minister of Education and Science, Javier Solana (afterwards General Secretary of NATO and Council Secretary-General of EU), trying to update the Spanish universities. They were responsible for introduction the now-well-accepted idea that university staff should necessarily combine lecturing and research. The result of the actions initiated by Luis Oro in the eighties, was an increase,- which could almost be described as spectacular,- 
of the Spanish contribution to the scientific production in all areas, value that has gone from $0.5 \%$ to $3.3 \%$ nowadays.

Since 2012 Luis Oro is member of the 'Spanish Advisory Council for Science, Technology and Innovation', where just a ten of internationally recognized scientists of different areas give direct advice to the Spanish Government at the highest level.

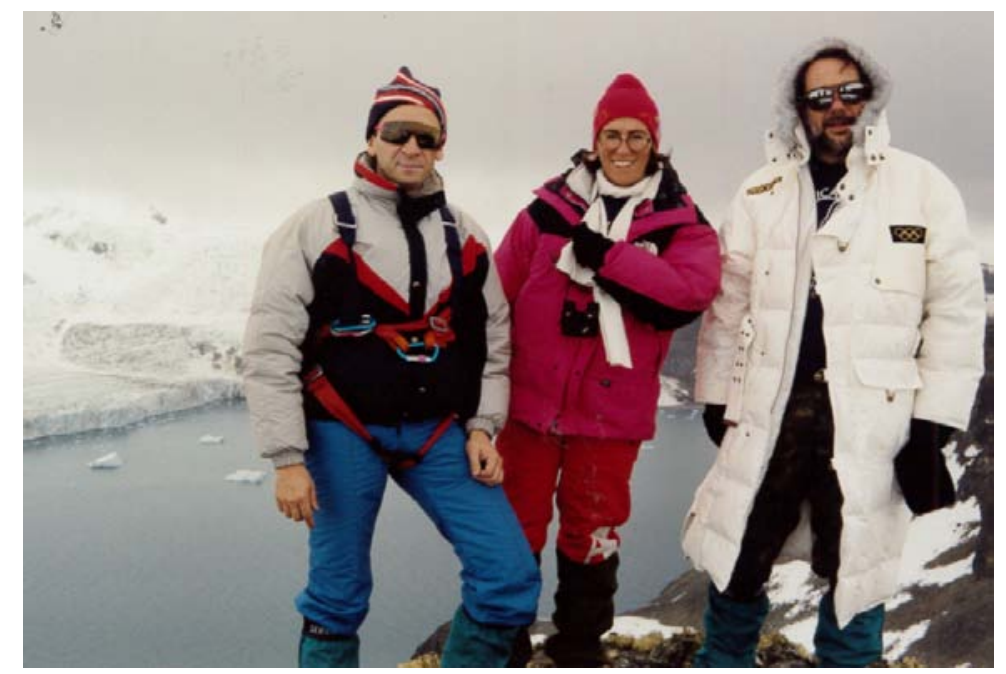

Luis Oro with the Science and Education Minister, Javier Solana, and other researchers visiting the Spanish Research Antarctic Base Juan Carlos I (1992, Livingston Island, Antarctica)

Luis Oro has also contributed in many different ways to the management and evaluation of science policy in diverse regional governments or research agencies. He is nowadays in the Advisory Boards of Science and Technology of Aragón and Valencia autonomous region and participates in the evaluation committees for talent recruitment of Cataluña (ICREA) or in the Basque country (IKERBASQUE). He has also been the President of the Spanish Royal Society of Chemistry during the period 2001-2005, and member of the advisory Board of the Catalonian Institute for Chemical Research (ICIQ) during its starting period (2004-2014), currently a centre of reference in chemical research in the world.

In 2003, the Aragón local Government decided the creation of a very limited number of research institutes trying to incentive research and development activities in the autonomous region; they challenged Luis Oro to create a research centre on Homogeneous Catalysis. He took the challenge, and as usual, working hard with the help of José A. Mayoral and Jesús J. Pérez-Torrente, and with other senior colleagues, they founded the University Institute for Homogeneous Catalysis (IUCH) in 2004. He 
was the IUCH Director from its creation to its re-foundation in 2013 to configure the current Institute for Chemical Synthesis and Homogeneous Catalysis (ISQCH). During his direction, Luis Oro made this Institute to become highly prestigious and an international reference in Homogeneous Catalysis.

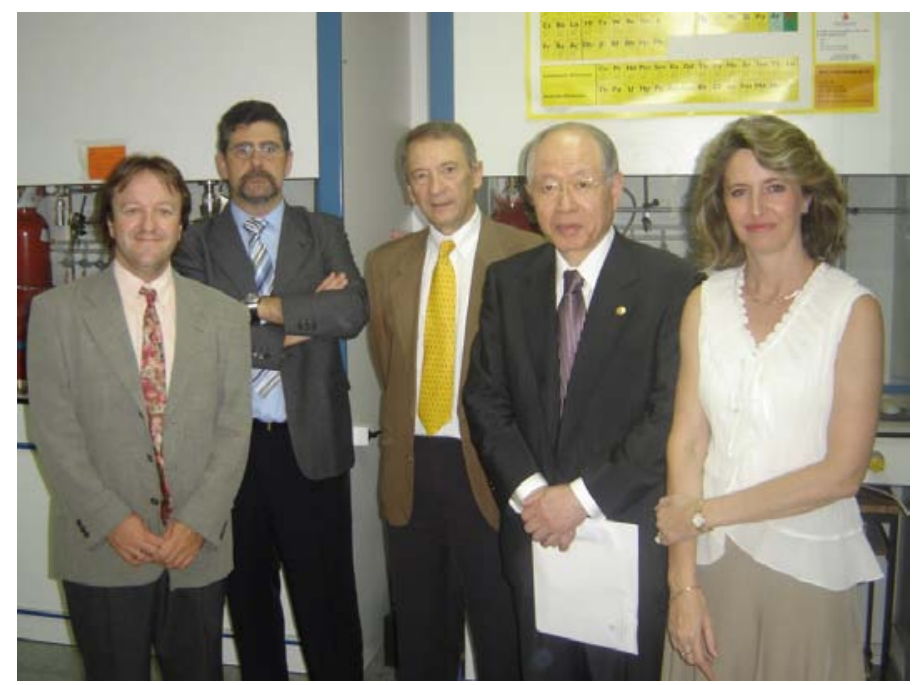

Prof Noyori during his visit to the Instituto Universitario de Catálisis Homogénea (IUCH). From left to right: Jesús J. Pérez-Torrente, José A. Mayoral, Luis A. Oro, Rioji Noyori and Anabel Elduque. (2006, Zaragoza)

(Prof. J. A. Mayoral text around here)

At an international scale, Luis Oro has also assumed several duties in the European and Ibero-American context. Between 1997 and 2002, he participated the CYTED Spanish initiative to strengthen the collaboration across the Atlantic Ocean with Latin-American countries; he coordinated during five years a quite productive Ibero-American network on Homogeneous Catalysis, program that helped to introduce or develop this field in most of the ibero-transatlantic countries. He also participated, as external advisor, in the committee who marked the basic lines for the reform of the Science policy in Chile (Millennium Scientific Initiative of Chile Government, 2005-2011). 


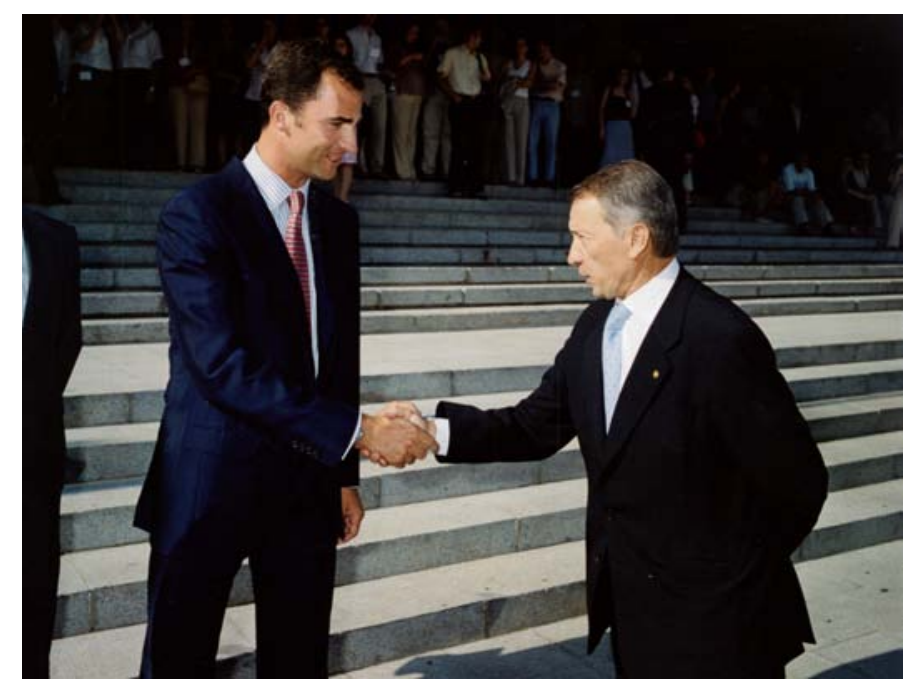

Luis Oro, as president of the Spanish Royal Society of Chemistry (RSEQ), meets his majesty the

King Felipe VI, on occasion of the first century celebration of RSEQ (2003, Madrid)

Luis Oro has also been active in the configuration of science policy in the European Union. For more than six years, he was member of the CREST Committee (European Union Scientific and Technical Research Committee Internationalisation) giving main lines to articulate $R \& D$ strategies in Europe, and to develop proactive international science policies. During six additional years (1993-1998), he took the vice-presidency of the European Science Foundation (ESF), stimulating European research through networking and coordinated activities. He also participated as elected member in European Science and Technology Assembly (1997-1999). In all these positions, he is remembered by his inexhaustible capacity for work, by his ground-breaking ideas and by his vehemence in discussions, just a consequence of his deeply sincere convictions.

In the very recent times, he has been the President of the European Association for Chemistry and Molecular Sciences (EuCheMS) in the period 2008-2010, just soon after the change in name in 2004 from the old FECS (Federation of European Chemical Societies) to EuCheMS, where the 'European' scope and the 'Molecular Sciences' fields were reinforced. He certainly strengthened the association, reviewing its governance structures and adding more strength to the independent voice for Chemistry that EuCheMS represents in Europe.

Although not having a profound knowledge of economy, but possessing a demonstrated creative mind, plenty of common sense, Luis Oro was invited in 2009 to join the Global Forum for Science of the OECD, the international Organization for Economic 
Collaboration and Development, where he tried to emphasize the relevance of R\&D policies for better lives, pushing all the time his Forum partners to understand the importance of Chemistry in nowadays world. He left this forum in 2013.

Currently, since 2002, Luis Oro is one of the four presidents of ChemPubSoc Europe. He was one of the negotiators in the initial discussions in the 90's for the publishing consortium dreaming, at that time, of the possible amalgamation of diverse chemical journals owned by national chemical societies into a number of high-quality European journals. Two decades later, his dream is a reality and ChemPubSoc Europe is a very successful organization of 16 European chemical societies, sharing a commitment to scientific excellence.

\section{(Prof. Wolfram Koch text around here)}

\section{Recognition by colleagues and other activities}

From what is written above, it should be clear to the reader the high mobility of Luis Oro along all his professional activities. He always tries to communicate to all his disciples the convenience of a personal contact with colleagues: "talking with colleagues you quickly discuss all minor details of an experiment, and additionally you could open collaboration projects and even establish good friendship links", he says.

It has been (and it is!) quite usual to find Luis Oro in international meetings on inorganic chemistry, organometallics or catalysis, or making short visits to colleagues to discuss some results or a collaborative paper. He has also contributed to their organization being chair or co-chair in some relevant conferences in this area. We can mention the 'VI European Research Conference on Inorganic Chemistry' (2000), the '13 $3^{\text {th }}$ International Symposium on Homogeneous Catalysis' (Tarragona, 2002), the 'Symposium on Mechanisms in Homogeneous Catalysis' (Ottawa, 2003), the 'XXII International Conference on Organometallic Chemistry' (Zaragoza, 2006) or the 'Symposium on Homogeneous Transition Metal Catalysis' of the IUPAQ World Chemistry Congress (Puerto Rico, 2011). We still have intense memories from the 2006 ICOMC Luis Oro chaired in Zaragoza... ten days before the deadline for registration we had only less than 300 participants registered. We need at least 600 to equilibrate our economy! We had prepared everything to have around 900 people. Luis and all his team were close to a heart attack. Fortunately, we were lucky and ten days later we had more 
than 1300 colleagues willing to participate in ICOMC2006... Two months before the date of the meeting we had to change the conference venue but we managed to accommodate all the participants. We ended having a quite successful meeting!

Luis Oro has been visiting professor in several universities exchanging experiences and collaborating with different colleagues (Bordeaux, Strasbourg, Wurzburg, Münster, or Taiwan). He always maintains his mind open to learn new processes, theories or techniques, but he is also ready to give the best of himself to help to understand any problem or willing to participate as another team member in any challenging project. His strong implications with some groups have merited him to be distinguished with the degree of Doctor Honoris Causa by the University of Rennes (2005) and very recently by the University Rovira I Virgili of Tarragona (2015). At the same time, he has also been generous to recognized the extraordinary contributions to the field of other colleagues promoting the same honour to Prof. Richard Schrock or Prof. Helmut Werner.

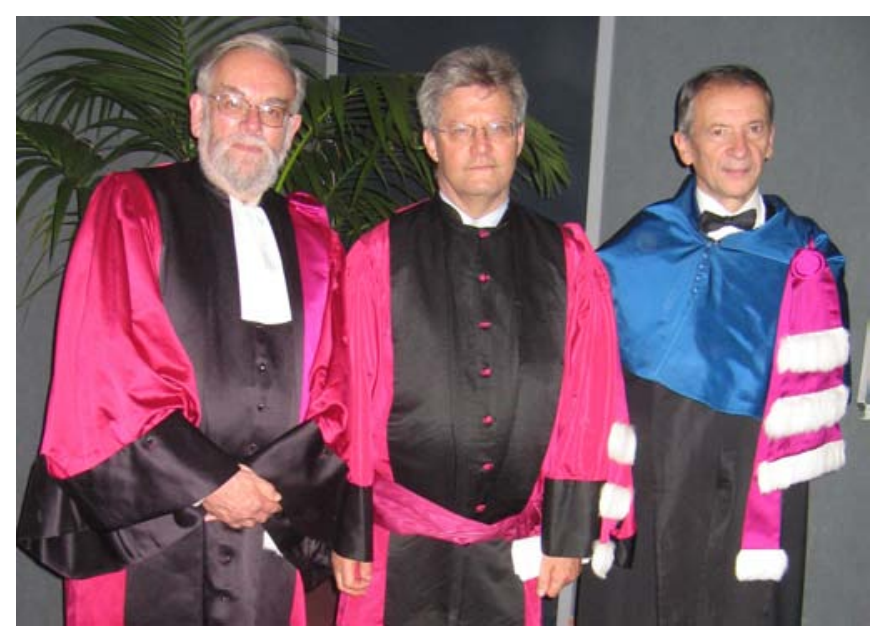

After getting his Doctorate Honoris Causa in the University of Rennes, together with Prof. Michael Bruce (left) and Prof. Pierre Dixneuf (centre) (2005, Rennes).

(Prof. Pierre Dixneuf text around here)

Luis Oro contributions to chemistry and science policy has been recognized with several prizes from private and public institutions, inside and outside his native country. Just mentioning the most relevant we should talk about the Solvay Prize (1989) given by the homologous company founded by Ernest Solvay, the Humbold Prize (1995), the French Chemical Society Catalán-Sabatier Prize (1997) or the Italian Chemical Society Sacconi Medal (2003) for his outstanding chemical research. 


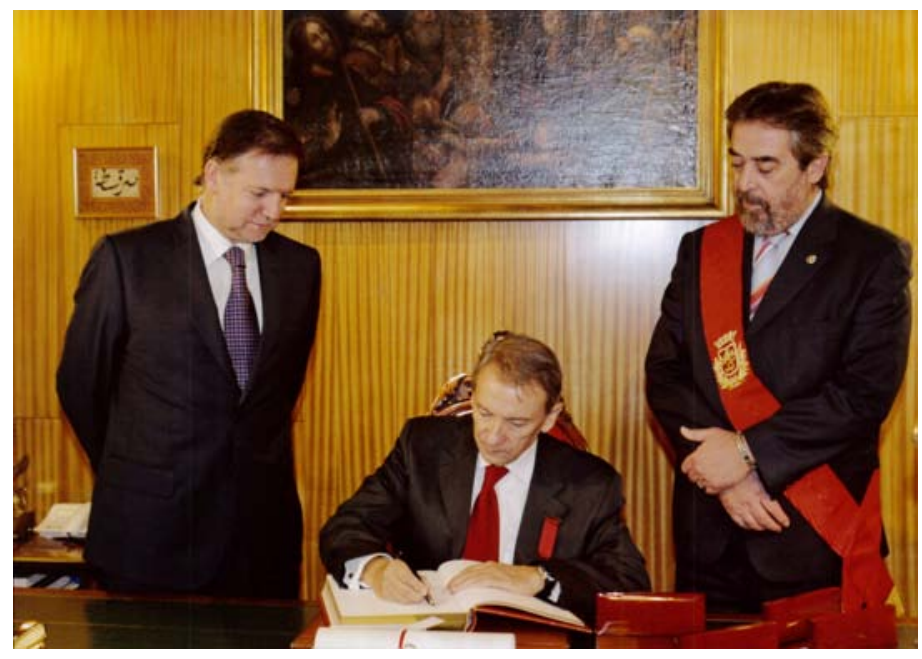

Receiving the Aragón Prize, together with Mr. Marcelino Iglesias, President of regional Aragón Government, and Mr. Juan Alberto Belloch, Mayor of Zaragoza (2001, Zaragoza).

Other prizes Luis Oro received valued both his scientific career together with his dedication to science policy and discovering. In his native region Aragón, he was awarded in 2001 the maximum distinction given in the area of culture, science and technology, the Aragón Prize, and the Zaragoza Gold Medal of his native town (2007); he received the Jaime I Prize, for a life dedicated to basic research (1999), the Chemical Research Lectureship Award in Taiwan (2002), the Japan Society for the Promotion of Science Award (2003), the Schulich Lectureship in Technion (Israel Institute of Technology) (2008), and the Research Prize and Gold Medal of the Spanish Royal Society of Chemistry (2007).

A special meaning for Luis Oro has the granting of the Spanish National Award on Chemical Science "Enrique Moles", prize directly received from the hands of the his majesty the King Juan Carlos I. In this case his leading discoveries in organometallic chemistry and homogeneous catalysis were on the basis of the jury statement. Also of particular relevance has been the EuCheMS for Service Award received last year 2014, for his outstanding fostering of chemistry and molecular sciences in Europe, and for his hard work leading EuCheMS. 


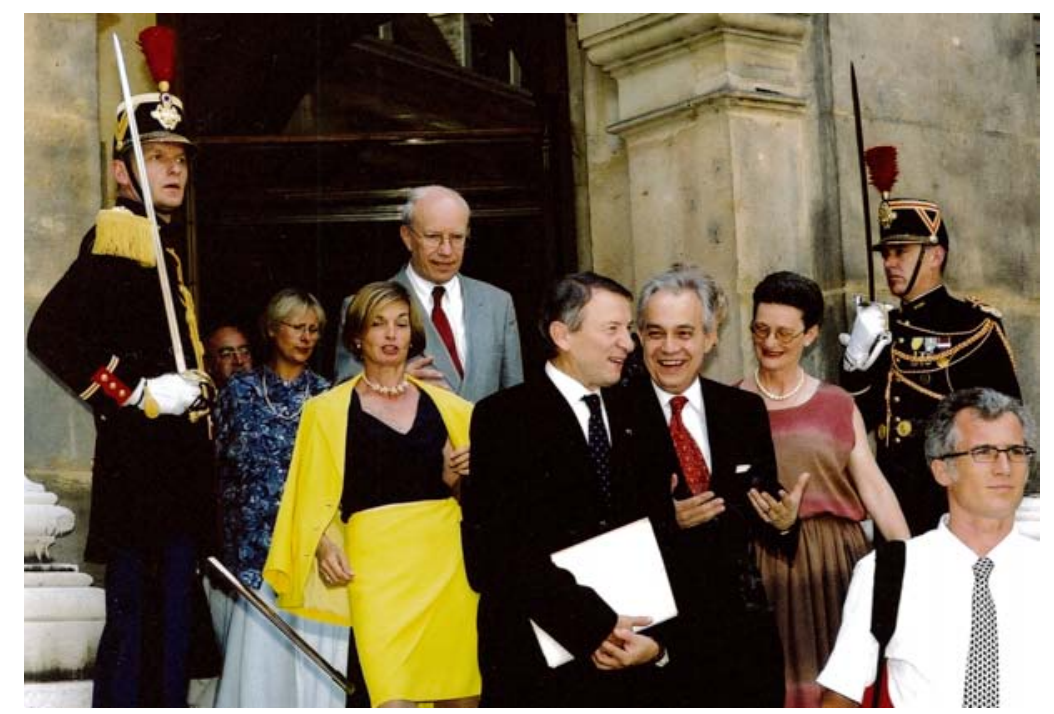

Luis Oro going out of the French Academy of Sciences followed by his wife and Prof. Pierre Braunstein (2002, Paris)

Another mention of Luis Oro's prestige is his nomination for membership at prestigious scientific Academies, such as the New York Academy of Sciences (1994), the French Académie de Sciences (2002), the German National Academy of Sciences Leopoldina (2006) and the Hungarian Academy of Sciences (2007). He has been also asked to carry out scientific activities of international relevance, as the invitation to write or participate in publications that are nowadays key sources in today's chemistry. We can mention, for instance, his guest authorship in the Encyclopedia of Catalysis with a chapter on Hydrogenation by Homogeneous Catalysis, and his contribution in the The Handbook of Homogeneous Hydrogenation. He has been co-editor of the three volume book on Metal Clusters in Chemistry, and the book Iridium Complexes in Organic Synthesis.

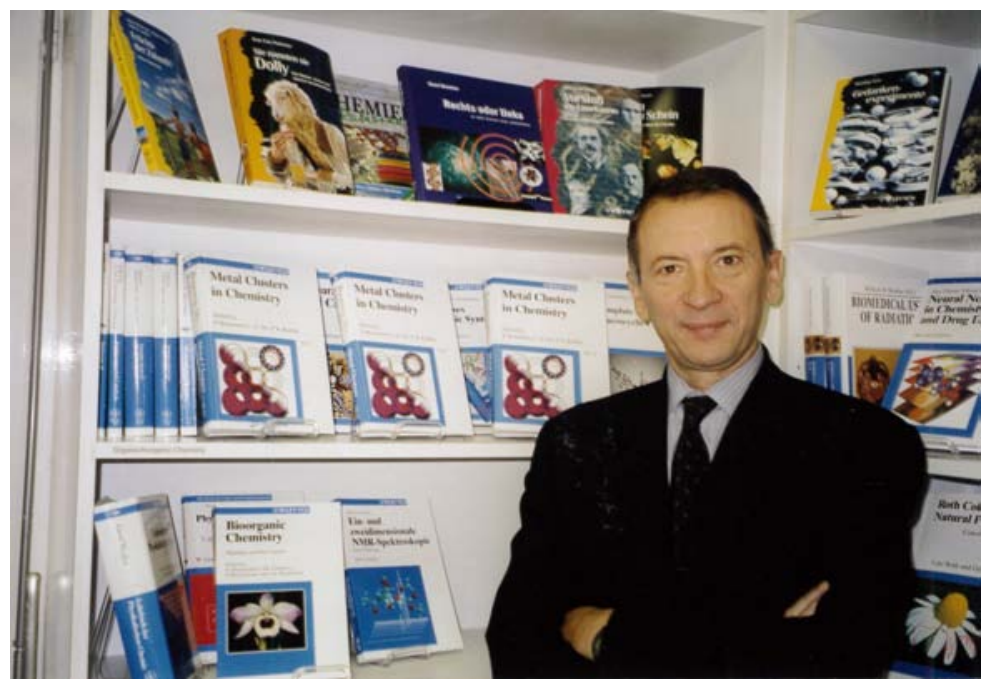

Luis Oro in Willey headquarters after the publication of "Metal Clusters in Chemistry" in 1999. 


\section{Reaching for the summit}

In his scientific career Prof Luis Oro has been all the time working to reach very high summits. Chemistry research has been his first passion, but certainly he has others. At least there is another one we know and he has been able to enjoy from time to time, that is mountaineering, climbing and trekking in the mountains.

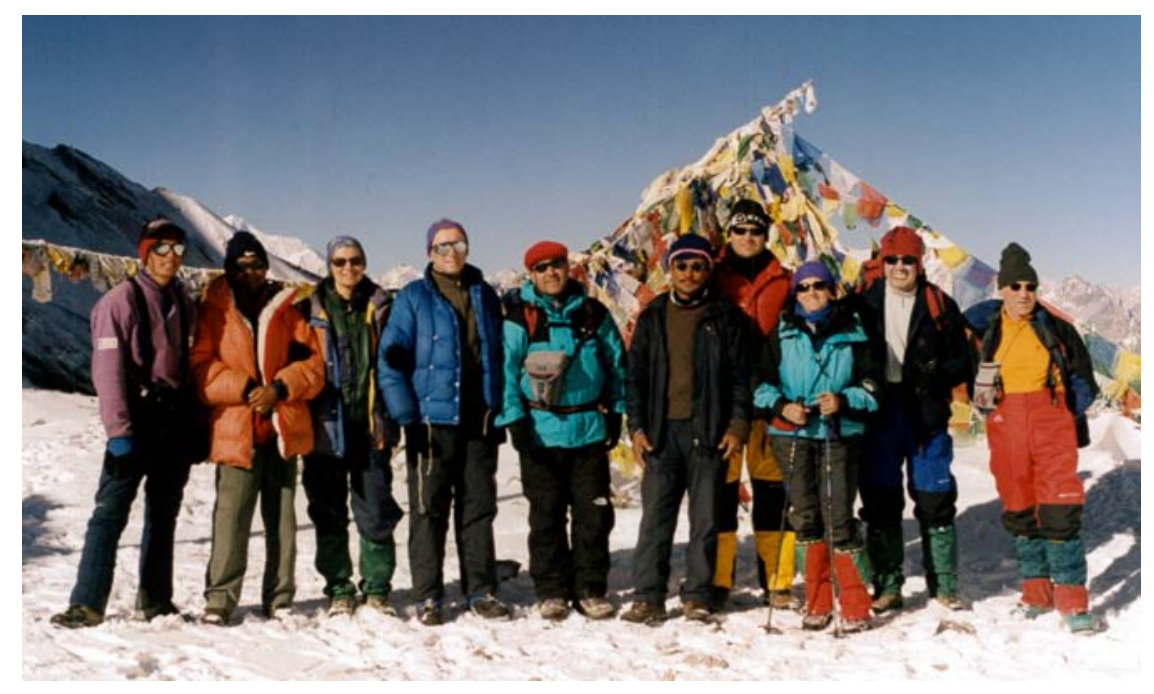

Luis Oro (fourth on the left) with some friends in the Thorung Pass (5416 m.) during the winter Annapurna trek (2004, Nepal)

From his summer periods in the Pyrenees as teenager, he has maintained a deep love for mountains and for mountain sports. I read somewhere Luis Oro saying: "If I were not chemist, I would have liked to be a mountain guide; two of my friends became professionals at this activity and I still love to climb mountains with them". Unfortunately during his more intense period involved in research and administration duties his dedication to his second passion was partially set aside. As far as I know, in the last years he has given to his second passion a higher priority and from time to time he escapes for long weekends to the Pyrenees or he organizes some not-very-smooth treks with friends in the Himalayas.

I had the opportunity to lead a trek with my friend Luis in the Himalayas ten years ago, although in fact I should admit he was leading the group most of the time!. During those days, I could also discover, in these very different circumstances, not only his mental strength -I already knew- but also his capacity to lead any group any time... just a 
consequence of his extraordinary capacity to persuade friends to work together for exciting challenges.

Just a real challenge was his last expedition in 2008. To celebrate the 40th anniversary of a mountain expedition in Morocco, he and three friends, all over 60 years old, climbed a peak of about 6600 metres in Nepal. He said: 'To summit it with my old friends was a fantastic experience'.

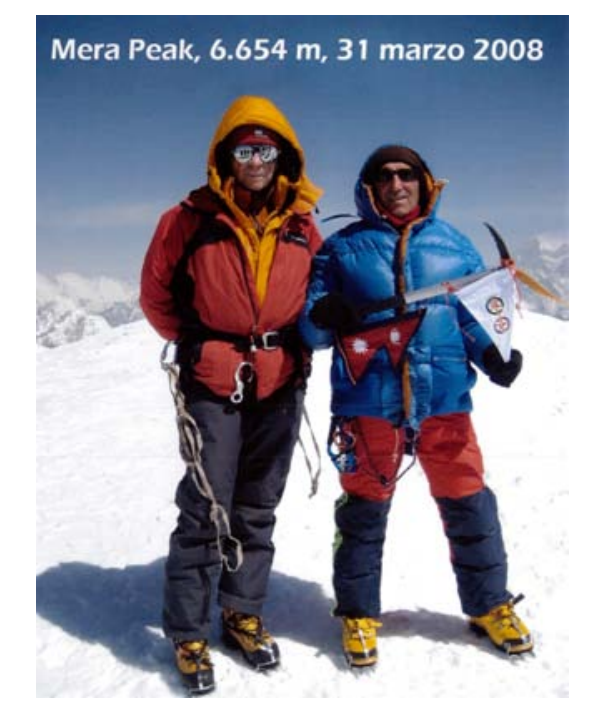

Luis Oro (left) and his friend Ursicino Abajo (2008, Nepal)

I think that climbing many other chemical summits with Prof. Luis A. Oro has been for most of his disciples, for most of us, a real exciting experience. We know you still have many summits still to climb in your mind. You still have plenty of time to work on it. Enjoy it! 


\section{References}

1.- a) C. Cativiela, J. Fernandez, J. A. Mayoral, E. Meléndez, R. Uson, L. A. Oro, M. J. Fernandez, J. Mol. Catal. 1982, 16, 19-25. b) L.A. Oro, J. A. Cabeza, C. Cativiela, M. D. Díaz De Villegas, E. Meléndez, J. Chem. Soc., Chem. Commun. 1983, $1383-1384$.

2.- R. Usón, L. A. Oro, M. A. Ciriano, M. T. Pinillos, A. Tiripicchio, M. Tiripicchio Camellini, J. Organom. Chem. 1981, 205, 247-257.

3.- a) D. Carmona, F. J. Lahoz, L. A. Oro, M. P. Lamata, S. Buzarra, Organometallics 1991, 10, 3123-3131, b) D. Carmona, M. P. Lamata, J. Ferrer, J. Modrego, M. Perales, F. J. Lahoz, R. Atencio, L. A. Oro, J. Chem. Soc., Chem. Commun. 1994, $575-576$.

4.- D. Carmona, J. Ferrer, A. Mendoza, F. J. Lahoz1, J. Reyes, L. A. Oro, Angew. Chem. Int. Ed. 1991, 30, 1171-1173.

5.- L. A. Oro, M. T. Pinillos, C. Tejel, C. Foces-Foces, F. H Cano, J. Chem. Soc., Dalton Trans. 1986, 1087-1094.

6.- L. A. Oro, M. A. Ciriano, J. J. Pérez-Torrente, B. E. Villarroya, Coord. Chem. Rev. 1999, 193-195, 941-975.

7.- L. A. Oro, M. A. Ciriano, C. Tejel, Pure Appl. Chem. 1998, 70, 779-788.

8.- M. A. Ciriano, S. Sebastián, L. A. Oro, A. Tiripicchio, M. Tiripicchio-Camellini, F. J. Lahoz, Angew. Chem. Int. Ed. 1988, 27, 402-403.

9.- C. Tejel, M. A. Ciriano, B. E. Villarroya, J. A. López, F. J. Lahoz, L. A. Oro, Angew. Chem. Int. Ed. 2003, 42, 529-532

10.- J. Barberá, A. Elduque, R. Giménez, L. A. Oro, J. L. Serrano, Angew. Chem. Int. Ed. 1996, 35, 2832-2835.

11.- M. J. Fernandez, J. Modrego, M. J. Rodriguez, M. C. Santamaria, L. A. Oro, J. Organom. Chem. 1992, 441, 155-158.

12.- M. P. García, A. M. López, M. A. Esteruelas, F. J. Lahoz, L. A. Oro, J. Chem. Soc., Chem. Commun. 1988, 793-795. 
13.- M. A. Esteruelas, L. A. Oro, Adv. Organom. Chem. 2001, 47, 1-59.

14.- M. P. García, L. A. Oro, F. J. Lahoz, Angew. Chem. Int. Ed. 1988, 27, 1700-1702.

15.- M. P. García, M. V. Jiménez, L. A. Oro, F. J. Lahoz, P. J. Alonso, Angew. Chem. Int. Ed. 1992, 31, 1527-1529.

16.- D. Carmona, A. Mendoza, F. J. Lahoz, L. A. Oro, M. P. Lamata, E. San Jose, J. Organomet. Chem. 1990, 396, C17-C21.

17.- a) D. Carmona, M. P. Lamata, F. Viguri, I. Dobrinovich, F. J. Lahoz, L. A Oro, Adv. Synth. Catal. 2002, 344, 499-502, b) M. Lasa, P. López, C. Cativiela, D. Carmona, L. A. Oro, J. Mol. Catal. A-Chem. 2005, 234, 129-135, c) D. Carmona, J. Ferrer, M. Lorenzo, F. J. Lahoz, I. T. Dobrinovitch, L. A. Oro, Eur. J. Inorg. Chem. 2005, 1657-1664. d) D. Carmona, C. Vega, N. García, F. J. Lahoz, S. Elipe, L. A. Oro, M. P. Lamata, F. Viguri, R. Borao, Organometallics 2006, 25, 15921606.

18.- a) D. Carmona, M. P. Lamata, F. Viguri, R. Rodríguez, L. A. Oro, A. I. Balana, F. J. Lahoz, T. Tejero, P. Merino, S. Franco, I. Montesa, J. Am. Chem. Soc. 2004, 126, 2716-2717, b) D. Carmona, M. P. Lamata, F. Viguri, R. Rodríguez, L. A. Oro, F. J. Lahoz, A. I. Balana, T. Tejero, P. Merino, J. Am. Chem. Soc. 2005, 127, 1338613398.

19.- C. Tejel, Y.-M. Shi, M. A. Ciriano, A. J. Edwards, F. J. Lahoz, L. A. Oro, Angew. Chem. Int. Ed. 1996, 35, 633-634.

20.- C. Tejel, Y.-M. Shi, M. A. Ciriano, A. J. Edwards, F. J. Lahoz, L. A. Oro, Angew. Chem. Int. Ed. 1996, 35, 1516-1518

21.- L. A. Oro, M. A. Ciriano, J. J. Pérez-Torrente, M. A. Casado, M. A. F. HernandezGruel, C. R. Chimie 2003, 6, 47-57.

22.- M. A. F. Hernandez-Gruel, J. J. Pérez-Torrente, M.1 A. Ciriano, F. J. Lahoz, Luis A. Oro, Angew. Chem. Int. Ed. 1999, 38, 2769-2771.

23.- a) E. Sola, F. Torres, M. V. Jiménez, J. A. López, S. E. Ruiz, F. J. Lahoz, A. Elduque, L.A. Oro, J. Am. Chem. Soc. 2001, 123, 11925-11932, b) Y. Yuan, M. V. Jiménez, E. Sola, F. J. Lahoz, L. A. Oro, J. Am. Chem. Soc. 2002, 124, 752-753, 
c) M. V. Jiménez, E. Sola, J. Caballero, F. J. Lahoz, L. A.Oro, Angew. Chem. Int. Ed. 2002, 41, 1208-1211, d) M. Martín, O. Torres, E. Oñate, E. Sola, L. A. Oro, J. Am. Chem. Soc. 2005, 127, 18074-18084.

24.- M. Martín, E. Sola, O. Torres, P. Plou, L. A. Oro, Organometallics 2003, 22, $5406-5417$.

25.- a) M. Martín, E. Sola, S. Tejero, J. L. Andrés, L. A. Oro, Chem. Eur. J. 2006, 12, 4043-4056, b) M. Martín, E. Sola, S. Tejero, J. A. López, L. A.Oro, Chem. Eur. J. 2006, 12, 4057-4068.

26.- M. V. Jiménez, J. J. Pérez-Torrente, M. I. Bartolomé, F. J. Lahoz, L. A. Oro, Chem. Commun. 2010, 46, 5322-5324.

27.- M. V. Jiménez, J. J. Pérez-Torrente, M. I. Bartolomé, E. Vispe, F. J. Lahoz, L. A. Oro, Macromolecules 2009, 42, 8146-8156.

28.- A. Álvarez, R. Macías, M. J. Fabra, F. J. Lahoz, L. A. Oro, J. Am. Chem. Soc. 2008, 130, 2148-2149.

29.- M. V. Jiménez, J. J. Pérez-Torrente, M. I. Bartolomé, V. Gierz, F. J. Lahoz, L. A. Oro, Organometallics 2008, 27, 224-234.

30.- a) M. Iglesias, P. J. Sanz Miguel, V. Polo, F. J. Fernández-Alvarez, J. J. PérezTorrente, L. A. Oro, Chem. Eur. J. 2013, 19, 17559-17566, b) M. Iglesias, M. Aliaga-Lavrijsen, P. J. Sanz Miguel, F. J. Fernández-Alvarez, J. J. Pérez-Torrente, L. A. Oro. Adv. Synth. Catal. 2015, 357, 350-354.

31.- a) M. Blanco, P. Álvarez, C. Blanco, M. V. Jiménez, J. Fernández-Tornos, J. J. Pérez-Torrente, L. A. Oro, R. Menéndez, ACS Catal. 2013, 3, 1307-1317, b) M. Blanco, P. Álvarez, C. Blanco, M. V. Jiménez, J. Fernández-Tornos, J. J. PérezTorrente, L. A. Oro, R. Menéndez, Carbon 2015, 83, 21-31.

32.- R. Lalrempuia, M. Iglesias, V. Polo, P. J. Sanz Miguel, F. J. Fernández-Alvarez, J. J. Pérez-Torrente, L. A. Oro, Angew. Chem. Int. Ed. 2012, 51, 12824-12827.

33.- A. Di Giuseppe, R. Castarlenas, J. J. Pérez-Torrente, F. J. Lahoz, V. Polo, Luis A. Oro, Angew. Chem. Int. Ed. 2011, 50, 3938-3942. 
34.- A. Di Giuseppe, R. Castarlenas, J. J. Peréz-Torrente, M. Crucianelli, V. Polo, R. Sancho, F. J. Lahoz, L. A. Oro, J. Am. Chem. Soc. 2012, 134, 8171-8183.

35.- a) L. Rubio-Pérez, R. Azpíroz, A. Di Giuseppe, V. Polo, R. Castarlenas, J. J. PérezTorrente, L.A. Oro, Chem. Eur. J. 2013, 19, 15304-15314, b) R. Azpíroz, L. Rubio-Pérez, R. Castarlenas, J. J. Pérez-Torrente, L. A. Oro, ChemCatChem, 2014, 6, 2587-2592.

36.- R. Azpíroz, L. Rubio-Pérez, A. Di Giuseppe, V. Passarelli, F. J. Lahoz, R. Castarlenas, J. J. Pérez-Torrente, L. A. Oro, ACS Catal. 2014, 4, 4244-4253.

37.- R. Azpíroz, A. Di Giuseppe, R. Castarlenas, J. J. Pérez-Torrente, L. A. Oro, Chem. Eur. J. 2013, 19, 3812-3816.

38.- I. Mena, M. A. Casado, P. García-Orduña, V. Polo, F. J. Lahoz, A. Fazal, Luis A. Oro, Angew. Chem. Int. Ed. 2011, 50, 11735-11738.

39.- I. Mena, M. A. Casado, V. Polo, P. García-Orduña, F. J. Lahoz, Luis A. Oro, Angew. Chem. Int. Ed. 2014, 53, 9627-9631.

40.- B. Calvo, R. Macias, V. Polo, M. J. Artigas, F. J. Lahoz, L. A. Oro, Chem. Commun. 2013, 49, 9863-9865.

41.- D. Carmona, M. P. Lamata, A. Sánchez, F. Viguri, R. Rodríguez, L. A. Oro, C. Liu, S. Díez-González, F.Maseras, Dalton Trans. 2014, 43, 11260-11268.

42.- M. V. Jiménez, F. J. Lahoz, L. Lukešová, J. R. Miranda, F. J. Modrego, D. H. Nguyen, L. A. Oro, J. J. Pérez-Torrente, Chem. Eur. J. 2011, 17, 8115-8128. 